\title{
SHEMZA.DIGITAL: Participatory art as a catalyst for social change
}

\author{
Aphra Shemza \\ Art in Flux \\ London \\ UK \\ aphra@aphrashemza.com
}

\author{
Stuart Faromarz Batchelor \\ Art in Flux \\ London \\ UK \\ sfbatchelor@gmail.com
}

\begin{abstract}
This paper explores the historical discourse around migrant voices within British art history, why now is the time to address these subjects and how through the use of participatory digital art it is possible to educate for social change. The paper will focus in particular on shemza.digital, a digital and interactive participatory art project created by Aphra Shemza and Stuart Batchelor. The project was funded by Arts Council England and based on the work of the British/Pakistani painter Anwar Jalal Shemza.
\end{abstract}

\section{Digital art. Participatory art. Generative art. British art history. Decolonising art.}

\section{INTRODUCTION}

In the last ten years there has been a rethinking of the place of migrant artists within British art history. Artists who came over to the UK in the 50s \& 60s such as Frank Bowling, Avinash Chandra, Uzo Egonu, Donald Locke, David Medalla, Ahmed Parvex, Francis Newton Souza, Aubrey Williams and Li Yuan-chia (Dadi 2016) are being given the recognition that they deserve.

We find ourselves in a period of reflection where the old colonial attitudes that once dominated London's art world for many years are being challenged and British art history is being rethought. (Shemza 2016) This is reflected in key exhibitions held at major institutions in the last few years such as Migrations: Journey into British Art, Tate, 2012, Frank Bowling, Tate, 2019 and the radical Post-War: Art Between the Pacific and the Atlantic, 1945-65, Haus der Kunst, 2016-2017. The latter was curated by Okwui Enwezor and sought to 'reframe the origins of the postwar global order' (Bader 2019). It was the first time that migrant artists were exhibited alongside the more familiar names in this groundbreaking show.

These changes in historical discourse make it possible for new conversations to take place. In May 2020 protests were sparked across the world following the brutal murder of George Floyd at the hands of an American police officer. Black Lives
Matter (BLM) as a movement for Black rights took centre stage in the world's media as a catalyst for social change and education about racism and oppression. Following this on the 7th June 2020 Bristol protestors pulled down a statue of the slave trader Edward Colston and pushed it into Bristol harbour. There was a cry amongst the British public for the radical destabilising of accepted history and it became more relevant and pressing than ever to decolonise British art and life.

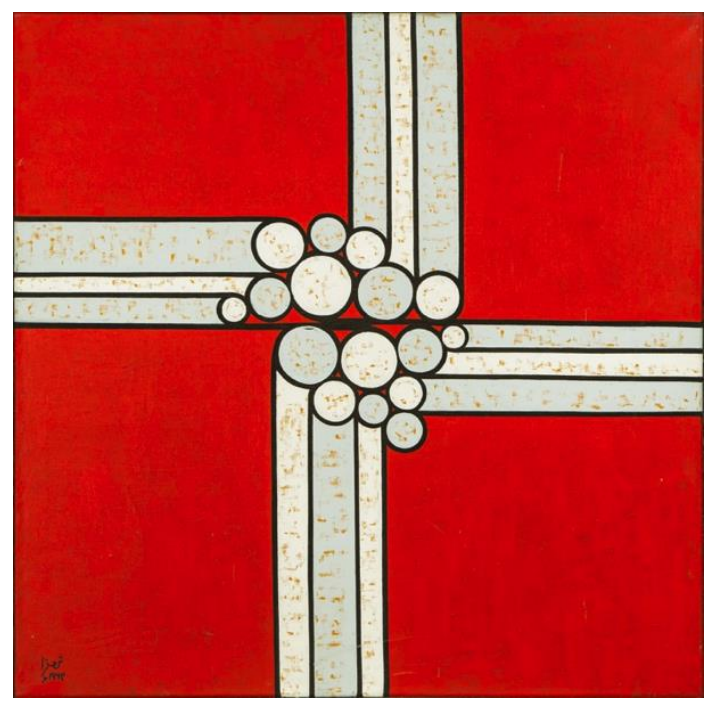

Figure 1: Anwar Jalal Shemza, Meem, 1964. The Butcher Family Collection. Image copyright Vipul Sangoi. 
With Nationalism increasing in the UK fuelled by Brexit and political and economic migration (Grant \& Price 2020) and calls to decolonise history following the Black Lives Matter movement, the British landscape is an increasingly polarised one. In the wake of the global Covid-19 pandemic the UK is on the brink of economic austerity and it is now more important than ever to celebrate the rich and diverse voices in our history as a way to bring society together in the face of adversity.

Just as the Black Lives Matter movement utilised the new social technologies of today to reach the masses with its political message, how might it be possible through participatory digital art to educate for social change?

\subsection{Participatory art as a means for social change}

The idea that art could be implemental in societal change has long since been prevalent in art history.

\begin{abstract}
Artists and arts organizations have been viewed as community leaders for decades and the choices they make often set the tone for how society approaches or reacts to certain issues and can often be a catalyst for change (Lewis 2009)
\end{abstract}

In relation to his own work, Joseph Bueys believed that 'as spectators became participants, the catalysis of social sculpture would lead to a transformation of society through the release of popular creativity' (Moore c.2010). Shemza.digital incorporates the language of participation, inclusion and accessibility to highlight the work of migrant artist Anwar Jalal Shemza and make digital art accessible to all, inviting the public to become artists themselves in order to provide education for social change.

\section{SHEMZA.DIGITAL: THE ARTISTS}

\subsection{Anwar Jalal Shemza}

Anwar Jalal Shemza (1928-1985) was a British/Pakistani artist who came over to London in 1956 to study at Slade school of Fine Art. Prior to his arrival he had achieved widespread recognition in Pakistan for his lyrical figurative works that drew inspiration from Mughal and Hindu themes. In 1952 he was a founding member of the Lahore Art Circle, a group concerned with Modernism and abstraction which included the artists Ali Imam and Ahmed Parvez.

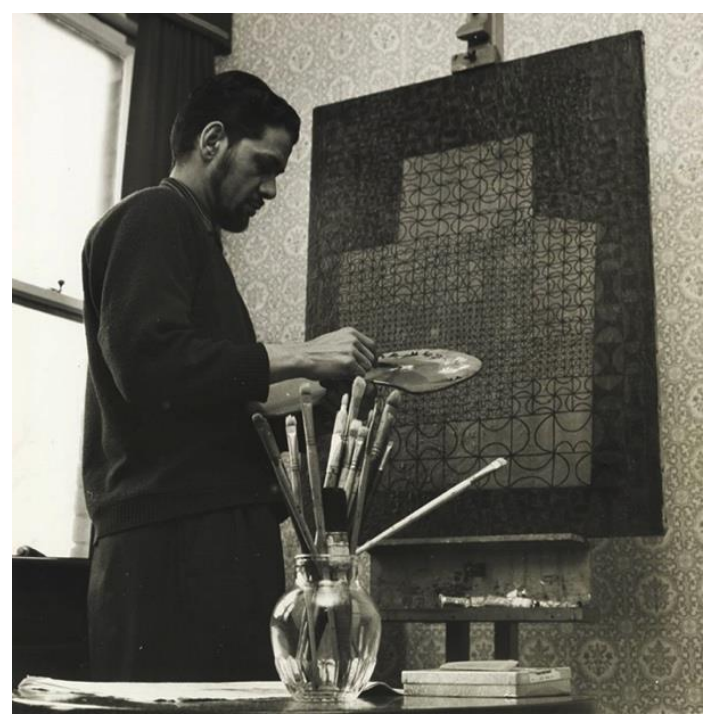

Figure 2: Anwar Jalal Shemza painting The Red House in his studio, 1960. Image courtesy of the Estate of Anwar Jalal Shemza.

When he arrived in London Shemza's Pakistani artistic achievements were not recognised. He was so disheartened by one of Ernst Gombrich's lectures in which the historian dismissed all Islamic art as purely functional that he subsequently destroyed all his work and began an exploration of the modernist abstraction of Klee, Mondrian and Kandinsky.

Later he would combine the simplified language of these artists with Islamic architecture and calligraphy to create his own unique style, for which he is well known today.

Anwar Jalal Shemza died suddenly from a heart attack in 1985. Since his death he has received widespread recognition with works in selected public collections including: Tate (UK), Sharjah Art Foundation, Metropolitan Museum, (USA), Guggenheim (Abu Dhabi), British Museum (UK) and $\mathrm{M}+$ Museum (Hong Kong). 


\subsection{Aphra Shemza}

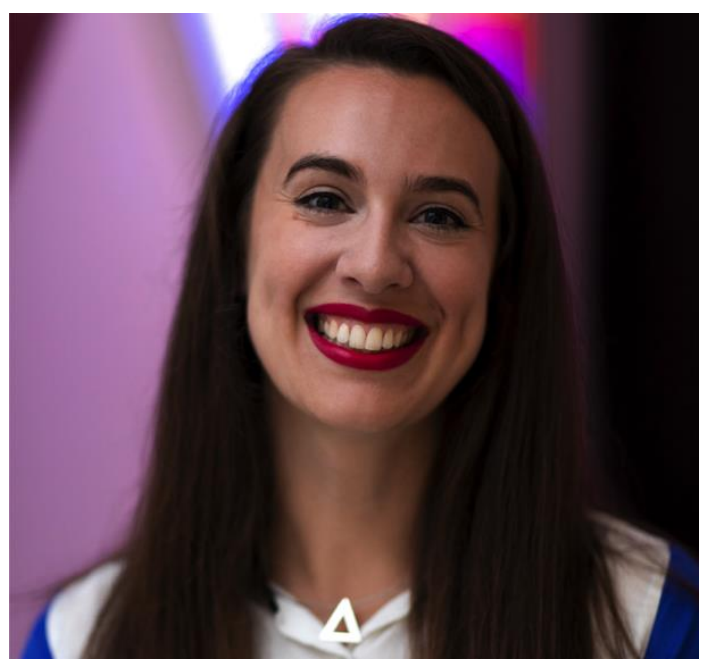

Figure 3: Aphra Shemza. Image by Matthew Kaltenborn.

Aphra Shemza, is a UK-based multimedia artist and the granddaughter of Anwar Jalal Shemza. Her work explores Modernism, her Islamic cultural heritage, sustainable practice and creating art for all. As an artist and activist she finds ambitious ways to fuse methodologies from the past with new innovations in technology to imagine what the role of art could be in the future.

Alongside her practice she is Manager of the Estate of Anwar Jalal Shemza and an expert in his work. In 2016 Shemza wrote a Tate etc. article which coincided with the spotlight display of his work at Tate Britain. She is currently cataloguing the Estate archive.

Shemza combines abstraction with traditional sculpting techniques and technology to create her work. As a sculptor her main medium is light, which she manipulates to create works that change over time. Handmade and bespoke interactive circuits are embedded within the pieces and this creates work which responds to the viewer or the space around it. Just as abstraction was said to be a 'universal language for the masses', Shemza has created a new visual language for a contemporary audience - one that explores the impact and legacy of technology on our world.

In March 2020 the global pandemic hit the UK and the country went into a National lockdown. The British cultural landscape changed overnight - the public were confined to their homes and cultural institutions closed their doors. Shemza was suddenly no longer able to exhibit her sculptures so she needed to find a way to create new work that retained her two core principles of participation and accessibility. Her solution was to translate them into the digital realm. Shemza.digital was born out of this exploration. Shemza would combine her knowledge of her grandfather's work with digital art to create a new participatory art project. The project would bring culture into the living rooms of the British public whilst they were at home self isolating and highlight the importance of diversity and community in these increasingly polarised times.

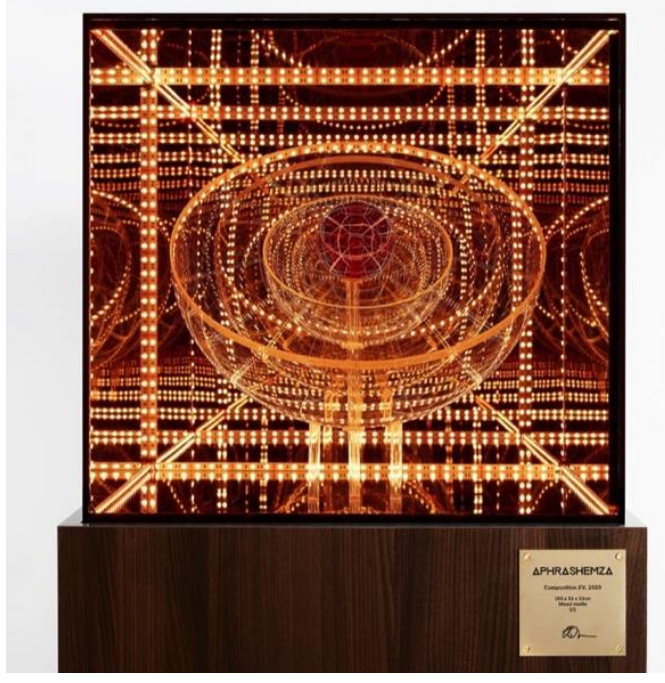

Figure 4: Aphra Shemza, Composition XV, 2020. Image by David Wilman.

\subsection{Stuart Batchelor}

Stuart Faromarz Batchelor is a London-based painter and computer artist who combines traditional media with custom software to create still, moving and installation work exploring visual phenomena and the relationship between maths, nature and our perception of meaning.

Alongside his artwork, Batchelor actively publishes research on enhancing creativity with computation. With a focus on the creative act of drawing and painting, Batchelor examines the disconnect often associated with both creating and engaging with digital artworks and how this could be remedied and even reversed.

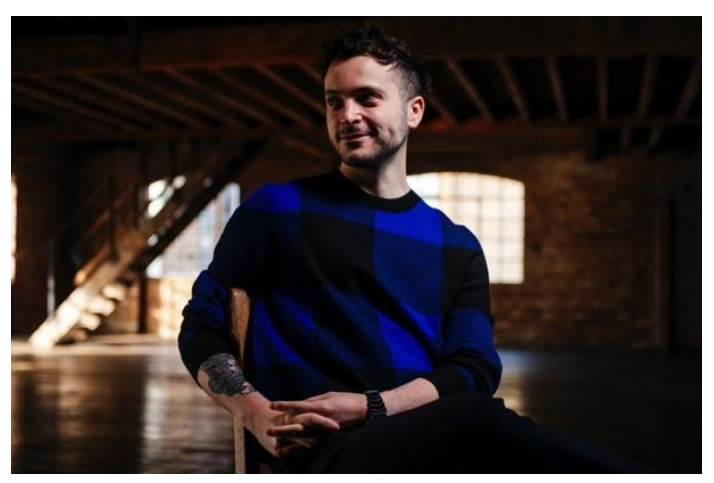

Figure 5: Stuart Faromarz Batchelor. Image by Matthew Kaltenborn. 
Though much of the materiality and tangibility of physical painting and drawing is lost when transferred over to the computer (Batchelor 2019), several advantages of digital media present unexplored avenues for creativity. By creating painting programs Batchelor examines this dichotomy that comes from using digital pigment. By encoding painting pigment through code, artists have access to a new form of expression, one that not only involves the placement of pigment but also the behaviour of it; how it animates, interacts with other pigments, reacts to real-time data such as audience presence or data-feeds.

In shemza.digital, Batchelor was afforded the opportunity to explore how drawing could be an act of learning our past and heritage. By encoding Shemza's most iconic aesthetics, could users get a deeper understanding of his artistic concepts, process and practice?

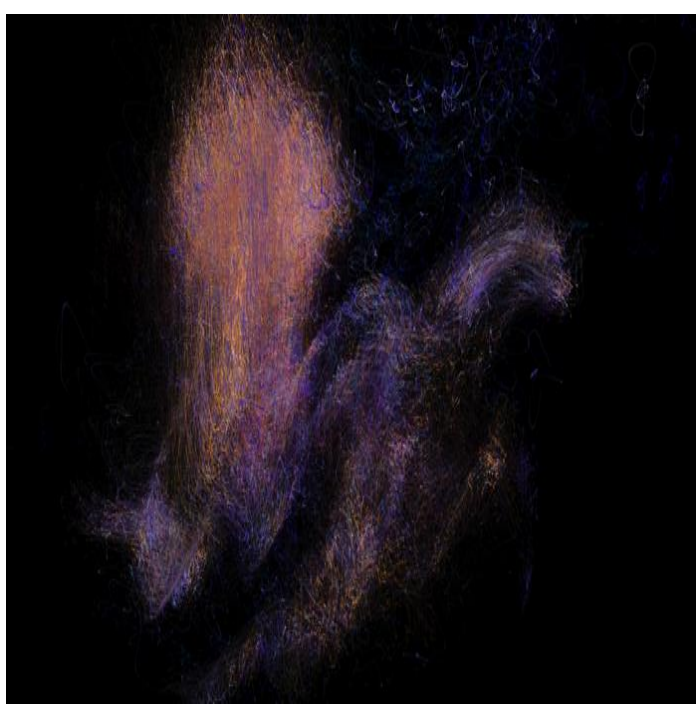

Figure 6: Stuart Faromarz Batchelor, Morganthau, 2020.

\section{GENERATIVE ART AS A MEANS FOR EDUCATION}

With generative art, the artist doesn't author a single or quantifiable number of works. Instead the artist indirectly creates works through designing a system with a set of boundaries and permutations which lead to the final work. The final artefact, an interactive user journey or static artwork, is just one possible outcome of the generative system.

The artist specifies a set of rules for a system, to generate a range of representations rather than authoring the representation itself (Bogost 2007). It is indirect, mutable and unique to the formal qualities of computers. Defining this art-domain is the generative artist's primary means of expression and in combination with the semi-randomness of audience interaction, creates a meaningful connection between participant and artist.

The audience's interaction with generative work allows for them to have autonomy and allows them to become an active contributor and collaborator. This act of doing, rather than passively consuming as in traditional artworks, lets audience members engage with creative ideas through their own actions, resulting in those ideas being retained and understood on a deeper level.

In shemza.digital, by encoding Anwar Jalal Shemza's motifs and style into a system and having that system mimic the interaction he had with those visual patterns, users could form a closer understanding of what Shemza's creative process was like. Through creating a drawing program that restricts the shapes to those of Shemza's style, users must think and arrange those elements within those boundaries, mimicking Shemza's own self imposed visual language.

\section{SHEMZA.DIGITAL}

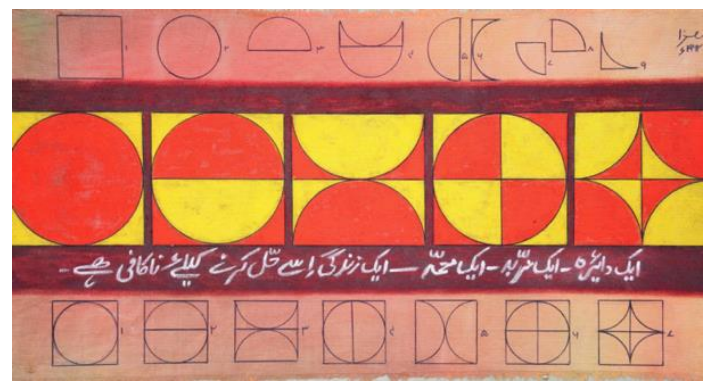

Figure 7: Anwar Jalal Shemza, One to Nine and One to Seven, 1962. Image courtesy of the Estate of Anwar Jalal Shemza.

In 1962, Anwar Jalal Shemza created the painting 'One to Nine and One to Seven,' which included an inscription in Urdu: "One circle, one square, one problem, one life is not enough to solve it". In shemza.digital Aphra Shemza and Stuart Batchelor use this as a starting point to continue Shemza's exploration.

The collaboration between the two artists combines Aphra Shemza's knowledge of her grandfather's work and making interactive and accessible artworks with Stuart Batchelor's programming skills and knowledge about generative art. By creating shemza.digital, 2020, a new online and interactive artwork, they ask the public to join them on this journey creating art that is free and accessible to all. 


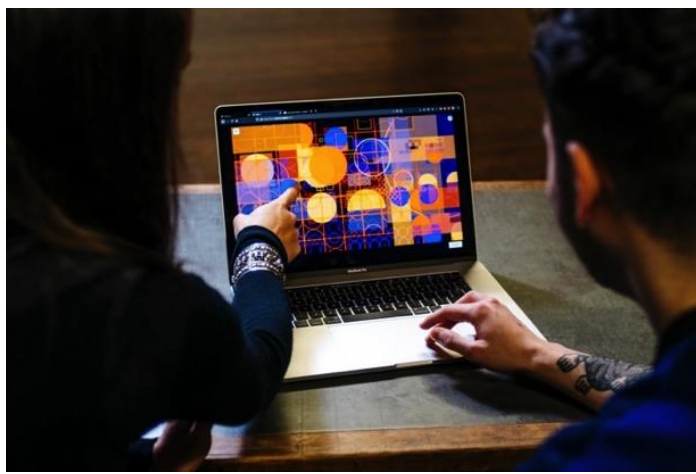

Figure 8: Aphra Shemza \& Stuart Batchelor creating shemza. digital 2020. Image by Matthew Kaltenborn.

The project was awarded an Arts Council England Project Grant for its creation in 2020 and launched on 18th November 2020 at Shifting Ground, an event curated by Aphra Shemza for Art in Flux and National Gallery X.

Since its launch shemza.digital has received over 1600 digital painting submissions to its online archive by the public and reached over 10,000 people through the use of online broadcasting, free teaching resources, workshops and social media and engagement campaigns.

Aphra Shemza and Stuart Batchelor are providing a unique tool set to make modern and contemporary art accessible to the wider public, not just as a passive observer, but as an active creator of computational art. This is the future of artistic practice. (Gingrich 2020)

\subsection{The user journey}

On entering the shemza.digital website the viewer is presented with a video which explains the project and its historical context. Once the viewer has watched the video they are prompted to PAINT NOW and move through to shemza.digital, 2020.

Shemza.digital, 2020 is an in-browser digital painting artwork that invites the public to create their own works in the style of Anwar Jalal Shemza. There are a number of functions in the application that the user can choose to action before submitting their work to an online database.

Shemza.digital has three digital paints each based on elements from Anwar Shemza's vast body of work. The Squircle paint combines a square and circle to produce colourful and scalable graphics.

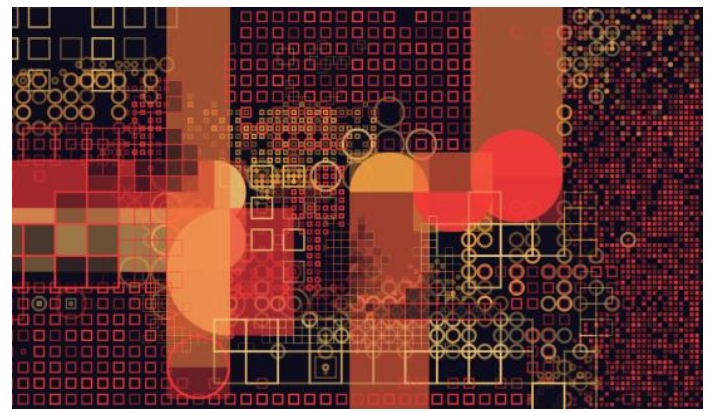

Figure 9: Stuart Batchelor, digital painting created using shemza.digital, 2020.
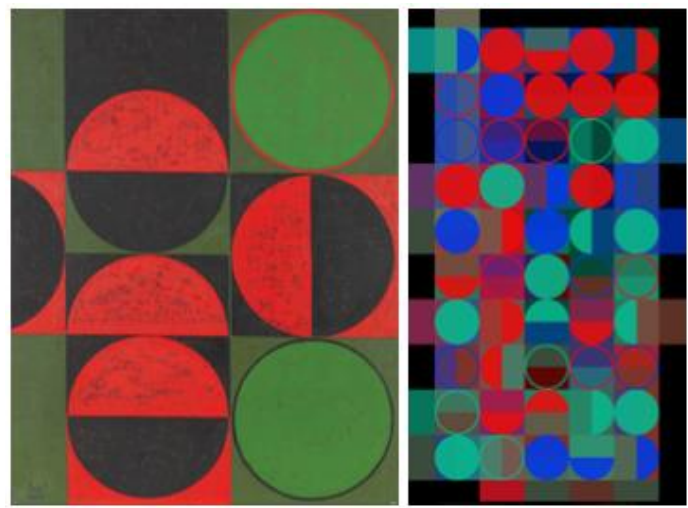

Figures 10 \& 11: Anwar Jalal Shemza, Composition in red and green, squares and circles, 1963. Tate

Collection. Image courtesy of the Estate of Anwar Jalal Shemza \& Stuart Batchelor artwork using the Squircle paint using shemza.digital, 2020.

The Weave paint references the woven motifs found in works like Love Letter Two, 1969 and relate to Shemza's heritage coming from a family of carpet makers in Pakistan.
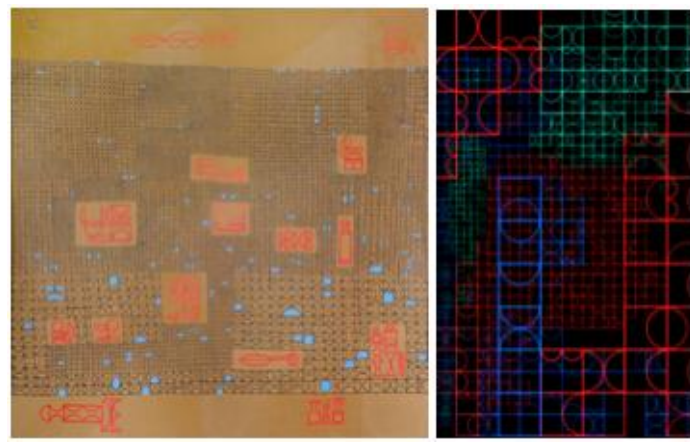

Figures 12 \& 13: Anwar Jalal Shemza, Love Letter 2, 1969. Image courtesy of the Estate of Anwar Jalal Shemza \& Stuart Batchelor, artwork using the Weave paint using shemza.digital, 2020. 
With the Mosaic paint the user can click and drag their mouse or finger across the canvas to leave a trail of squares and circles. This style can be found in Shemza's wooden reliefs from the 1960s.

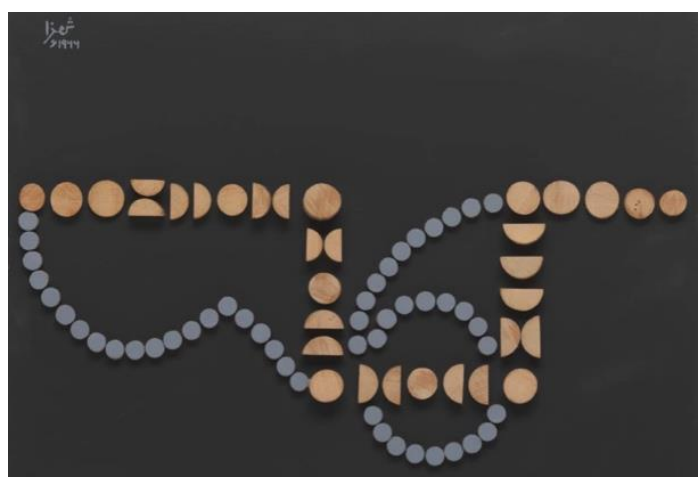

Figure 14: Anwar Jalal Shemza, Composition with Number Six, 1966. Tate Collection. Image courtesy of the Estate of Anwar Jalal Shemza.

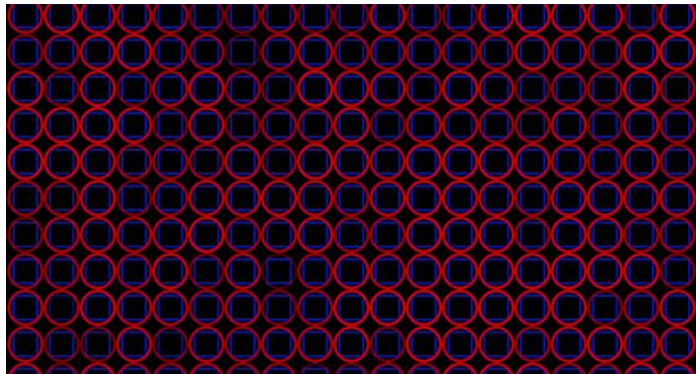

Figure 15: Daniele, Electric Blue, using the shemza.digital mosaic paint. One of the shemza.digital competition winners, 2021.

The user creates their digital painting using any combination of the three paints available. The paints are selected by using a button to switch between them. There are other limited functions within the software: the ability to undo a shape and choose the colour palette the work is being made in. The limited options have been chosen to simplify the process of creating a digital painting. The work relies heavily on the generative nature of the program and collaboration between user and computer. This element of randomness is crucial as it enables the widest number of participants to create visually pleasing work with minimal effort

Once finished the participant is invited to submit their work to the online archive. The contributions will be stored online and used to create a largescale generative light art installation in 2021/2022.

\subsection{How it works}

Shemza.digital is a ThreeJS Javascript canvas element application which uploads users' creations to a cloud storage database. After uploading, the user's paintings are then viewable inside the Archive Shemza.digital site-page.
The Archive is also a ThreeJS application that reads the cloud storage in real-time, allowing for almost instant viewing of participants' artworks. Through this, the audience gets a tangible sense of the scale of the project and a way to interact with the other participants.

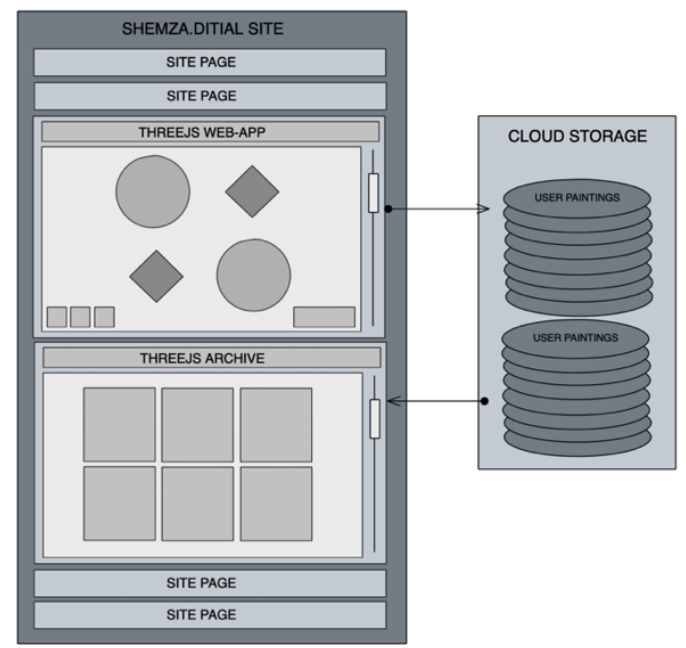

Figure 16: shemza.digital system diagram, 2021.

Going forward this system and the database of artworks will be extended and used as data for a physical real-time installation.

\section{ENGAGEMENT}

Shemza.digital is a project with multiple forms, the digital painting application sits alongside an engagement strategy which invites the public to take part to increase participation with the project. Through the use of social media, competitions, press campaigns, the creation of free teaching resources and community workshops, the project was able to reach a large number of the British public.

\subsection{Shemza.digital competition}

One of the most successful engagement strategies of the project was the shemza.digital competition. Held between 3rd and 15th February 2021, the competition had over 700 submissions. Out of these nine winners were selected to have their artworks combined into two collaborative digital artworks, one moving image work and another 3D animation The artwork was created for the Art in Flux: Reclaimed online exhibition and launched at National Gallery X on 30th March 2021. This was a wonderful opportunity for the public to have their work exhibited in an exhibition alongside some of the most radical media artists today. The winners' paintings were exported as real-time animations of the painting process and hung in 3D space to form shemza.digital \#1, the first in the series of collaborative works. 


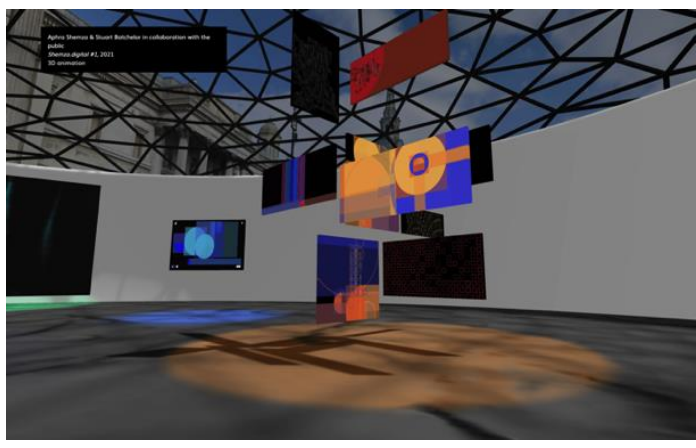

Figure 17: shemza.digital \#1, 2021, 3D animation exhibited in Art in Flux Reclaimed, virtual exhibition, 30th March-30th April, 2021.

By inviting the public to become equal participants in the creation process, shemza.digital is groundbreaking in showing participatory and community work in a professional media art context and reclaiming the once elite art and technology world for the public, making art that is accessible to all.

\subsection{Accessibility and participation}

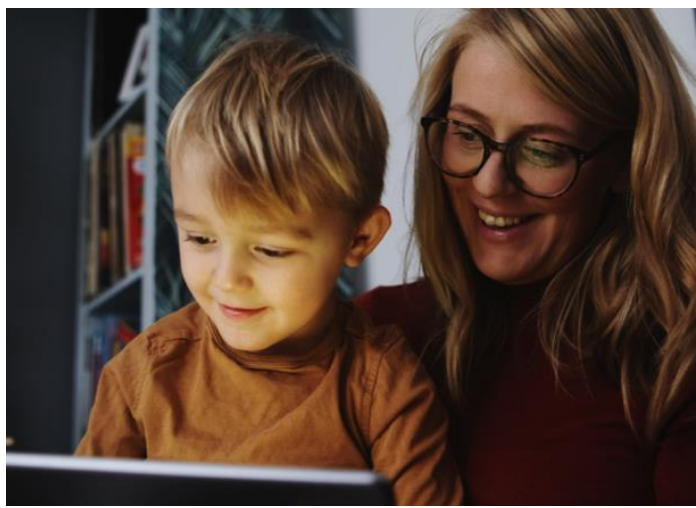

Figure 18: $A$ mother and her son using shemza.digital, 2020. Image by Matthew Kaltenborn.

In order to ensure that the project was accessible the team held a user test with 35 people before the project was launched. The testing was crucial to the project's success and led them to develop the artwork before the launch, implementing changes suggested by the process such as a help button which featured a how to video, clearer icons for the functions and a starting instruction 'click and drag to begin.'

Accessibility as well as usability was of utmost importance to the project, the painting application was made so that it functions on phones, tablets and computers. Mass engagement with the public also meant that the work had to be instantly usable and require little effort to produce a 'good' digital painting.

Because of the testing and focus on engagement the audience interacted with the artwork and its context in the way the team had hoped. From their feedback survey they could see people from as young as 3yrs to 88yrs had participated in the project and $98 \%$ of them had a good quality experience.

\section{I think all the artworks on the project are great... makes anyone feel they can be creative. It's a great way to practice mindfulness in these challenging times! (Clare 2020)}

It was also apparent from the feedback that not only did people enjoy themselves but they also engaged with the idea of decolonising the art world and the work of Anwar Jalal Shemza.

I had a great time painting in the style of Anwar Jalal Shemza on the website. Made me appreciate his work even more. (User tester 2020).

\section{THE FUTURE}

Shemza.digital has only just begun, over the next year the team will continue to engage the public with the project via community workshops and competitions. They will create a physical installation which combines all the participant's digital paintings. The goal of this is to provide a multi-form digital artwork that connects the virtual world with the physical, embodying the connective effect of creativity, our shared art history and the potential for artworks to be enhanced with digital capabilities.

Walter Benjamin maintained that a work of participatory art should actively provide a model for allowing viewers to be involved in the process of production and moving forward with the design of this physical installation the public will be involved in co-creation through workshops to further engage the already active community and truly make media art accessible to all.

[T]his apparatus is better, the more consumers it is able to turn into producers - that is the more readers or spectators into collaborators (Benjamin 1931-1934)

\section{CONCLUSION}

In conclusion even during times of adversity it is possible to bring culture into the homes of the British public through digital participatory art projects. The shemza.digital project has shown that there is an appetite for this kind of work and not only do the public engage with it but they are also able to take from it the deeper meaning of decolonising the art and life.

We believe that participatory digital art can be a catalyst for social change and we should utilise technology to bring us closer together, instead of propelling us apart. 


\section{REFERENCES}

Anonymous user tester. (2020) Testimonial user testing form.

Bader, G. (2016) Post war: Art between the Pacific and the Atlantic: 1945-1965. https://www.artforum.com/print/201607/postwar-artbetween-the-pacific-and-the-atlantic-1945-196562995 (20th March 2020).

Batchelor, Stuart. (2019) A Framework For Future Paintings. In: Weinel, J., Bowen, J.P., Diprose, G., and Lambert, N. (eds), EVA London 2019 (Electronic Visualisation and the Arts) 2019. doi: $\underline{10.14236 / \mathrm{ewic} / \mathrm{EVA2019} .59}$

Benjamin, W. (1931-1934) The Author as Producer. Harvard University Press, 2003) pp.777.

Bogost, I. (2007) Persuasive Games: The Expressive power of Videogames, Cambridge MA: MIT Press, p.4.
Broderick Lewis, J. (2010) The Art of Sustainability: Visual Arts Organisations and the Modern Environmental Movement. CSPA Quarterly, Volume 2 (1), pp.6-8.

Clare (2020) Testimonial user testing form.

Dadi, I. (2016). Anwar Jalal Shemza. Riding House, London, UK.

Gingrich, O. (2020) Testimonial user testing form.

Grant, C \& Price, D. (2020) Decolonising Art History.

https://onlinelibrary.wiley.com/doi/full/10.1111/1467 -8365.12490 (20th March 2021).

Moore, A.W. (2018) Brief Genealogy of Social Sculpture.

http://www.joaap.org/webonly/moore.htm (26th March 2018).

Shemza, A. (2016) My grandfather, Anwar Jalal Shemza. Tate Etc. 16th October 2016. 